\title{
Violencia, prostitución y reconstrucción de identidades
}

Violence, prostitution and identity reconstruction

\author{
LAURA PALLARÉS AMENEIRO \\ Universidad de Santiago de Compostela-Facultad de Geografía e Historia \\ laurameneiro@gmail.com \\ ORCID: https://orcid.org/0000-0002-2266-2254 \\ http://dx.doi.org/10.15304/sm.31.5982
}

\section{RESUMEN}

Este artículo que lleva por título "Violencia, Prostitución y Reconstrucción de identidades" tiene como objetivo principal poder demostrar como la prostitución como fenómeno y realidad social desde la antigüedad, ha estado marcado en la vida de cada una de las mujeres desde la infancia, por episodios temporales o continuos de violencia principalmente física, provocando una ruptura de identidad natural en las mismas.

Metodología en base a los conocimientos teóricos de Doreen Massey, entre otros, y prácticos, con trabajo de campo minucioso, a través de 9 entrevistas personales y 50 encuestas a sexoservidoras de la ciudad de México.

Los resultados obtenidos en función a la metodología utilizada confirman la reconstrucción de la identidad o neoidentidad de las prostitutas, sin filtros, sin doble personalidad y sin violencia.

Palabras clave: Violencia; Prostitución; Identidad; Espacio.

\section{Abstract}

This article entitled "Violence, Prostitution and Reconstruction of identities" has as main objective to demonstrate how prostitution as a phenomenon and social reality since ancient times, has been marked in the life of each of the women since childhood, by temporary or continuous episodes of mainly physical violence, causing a rupture of their natural identity.

Methodology based on the theoretical knowledge of Doreen Massey, among others, and practical, with meticulous fieldwork, through 9 personal interviews and 50 surveys of sex workers in Mexico City.

The results obtained based on the methodology used confirm the reconstruction of the identity or neo-identity of the prostitutes, without filters, without double personality and without violence.

Keywords: Violence; Prostitution; Identity; Space. 
El objetivo principal del presente artículo es reflexionar sobre las interrelaciones existentes entre la violencia, prostitución e identidad en base al territorio, y como a través de las prácticas y actividades ejercidas en el acto prostitucional y preconcebidas desde la infancia, desembocan en la búsqueda por parte de las mujeres de una nueva identidad o neoidentidad, en relación con el espacio donde la desarrollan.

Todos los elementos de los que forman parte estas acciones, nos llevará a tener claro unas conclusiones que buscamos en base a la metodología utilizada gracias a los conocimientos no solo teóricos del fenómeno, destacando la figura de Doreen Massey en cuanto identidad y espacio, entre otros; sino al trabajo de campo realizado en la Ciudad de México con mujeres que se prostituyen, 50 encuestas y 9 entrevistas personales, vidas marcadas en cierta forma, desde su infancia y tras años siendo sometidas por un sistema patriarcal, bajo falta de afectividad, maltrato, violación, humillación y estigmatización constante, sintiéndose como vacías en un espacio que consideran de otros, y que buscan en el medio prostitucional y fundamentalmente, en un territorio particular, donde poder desarrollar su actividad, cariño, afecto, comprensión, significado y en otras palabras, otras referencias identitarias, de ahí la importancia de la relación entre género y espacio.

Este artículo será estructurado en tres apartados que nos llevan a las conclusiones finales con respecto a la relación de los tres aspectos fundamentales a tratar, como refleja el título del artículo.

1. Aportes teóricos de identidad y su relación con el espacio,en base a la figura de Doreen Massey, así como prostituta, violencia y prostitución.

2. Aportes prácticos a través de encuestas y entrevistas personales a prostitutas de la ciudad de México.

3. Dominio de territorialidad y reconstrucción de identidades en la prostitución de calle de la Ciudad de México.

\section{APORTES TEÓRICOS DE IDENTIDAD, ESPACIO, PROSTITUTA, VIOLENCIA, PROSTITUCIÓN}

Hablar de estos tres elementos, violencia, prostitución e identidad, es hablar de la mujer y como desde que nace van forjando y conformando una identidad propia en base a diferentes factores familiares, históricos, culturales, sociales y económicos que harán que su trayectoria vital sea única y particular. Referencia de Marcela Lagarde (1990, p.1) al respecto de identidad de las mujeres como el "conjunto de características sociales, corporales y subjetivas que la caracterizan de manera real y simbólica de acuerdo con la vida vivida".

En base a estas premisas, consideramos fundamental establecer una definición teórica de los conceptos a tratar y que serán punto de partida para la reflexión de los mismos, pero es importante dejar claro la gran complejidad en torno a ellos, por lo que nos centraremos desde el punto de vista territorial, sin entrar en ningún tipo de debate. 
El primer concepto a resaltar es el de Identidad, como consecuencia del conocimiento, respeto, estudio, que solamente es posible manifestarla a partir del patrimonio cultural, que existe de antemano, y su existencia es independiente de su reconocimiento o valoración. Implica que las personas o grupos se reconocen históricamente en su propio entorno físico y social y es ese constante reconocimiento el que le da carácter activo a la identidad cultural (Bákula, 2000, pp.164-167)

Partimos del concepto de identidad, que proviene del término "idéntico", conjunto de rasgos propios de un individuo o de una colectividad que los caracterizan frente a los demás, aquello que una persona tiene de ser ella misma y distinta a los demás (R.A.E, 2016), es decir, que remite a la semejanza por encima de la diferencia, lo homogéneo más que a lo diverso. Podemos entender que esta definición, como se observa, es más ideológica que científica por las características que señala al sentirse el individuo y los grupos "idénticos" entre ellos (kravzov, 2003)

Identidad es un concepto complejo porque en él se incluyen elementos como raza, etnia, religión, costumbres desde distintas perspectivas, y que distinguen a un lugar, a su gente y le brindan identidad propia en su conjunto (Horton, 2013).

Este concepto se considera un proyecto simbólico donde los individuos o grupos forman una identidad con los elementos adquiridos en su vida en la interacción con otros al pasar el tiempo (Larrain, 2003). Esta teoría sobre el concepto de identidad como espacio simbólico tiene sus raíces en la percepción, como una propiedad inherente a la percepción de los espacios, donde en palabras de Valera (1996, pp.63-84) "derivan de las características físico-estructurales, de la funcionalidad ligada a las prácticas sociales que en éstos se desarrollan o de las interacciones simbólicas entre los sujetos que ocupan dicho espacio".

De esta forma de espacio es de donde deviene una de las definiciones de identidad, que relaciona la misma con las características sociales elaborando el concepto de identidad social urbana (Valera, 1997, pp.17-30).

Este sentido de pertenencia a una colectividad lo sitúa geográficamente pero no de manera generalizada, ya que inserta elementos no solo colectivos sino también individuales cargados de simbolismo, que lo hacen tener su propia identidad y particularidad.

Identidad conformada a lo largo del tiempo, a través de las poblaciones que viven en un determinado lugar, con unas características propias que lo hacen particular, por medio de las relaciones y condiciones sociales que se dan en la misma. Identidad marcada por sus gentes, sus raíces, su forma de pensar y de actuar, sus adquisiciones personales, sus sentimientos y sus huellas en el paso del tiempo. Por lo tanto, forjar una identidad es interrelacionar a las personas que viven en un espacio con los factores sociales que adquieren a los largo de la vida.

Importancia de la identificación en el espacio que lo hace particular y la diferenciación que se hace de los individuos en relación a los demás, dentro de un mismo espacio, constituyen los mecanismos de asimilación y diferenciación y estudiado por diferentes disciplinas, y en concreto, por la geografía cultural. Con esta interrelación de lo espacial 
con lo social, estamos hablando de la importancia de la identidad como parte de la Geografía Cultural (Molano, 2007, pp.69-84).

Estos estudiosos del concepto de identidad, definen la particularidad del mismo a través de la historia, es decir, identidad propia a través de las interrelaciones sociales, siempre en base a trayectorias de vida. Por ello, no puede desligarse este concepto de su circunstancia histórica y de todos los elementos que la rodean. Relación de la historia con el espacio que define la identidad de un lugar, forjándose una identidad individual o colectiva.

Importancia de los dos conceptos que aparecen a continuación para poder entender la búsqueda de identidad, el lugar y el barrio como parte integrante de la misma, a través de los cuales, las personas forjan su personalidad y la construcción en base a factores históricos, sociales, económicos, psicológicos, familiares que la hacen propia.

Sin las nociones de lugar y barrio es imposible entender la identidad de los sujetos, asociados siempre a un espacio en concreto, sin ser permanente, dado que la identidad puede ser creada temporalmente y desestructurada para crear una nueva o reconstruir la anterior, en función a las trayectorias de vida.

El concepto de lugar, ligado en todo momento al de identidad, representándose a sí mismo como una condición de experiencia humana, como agentes en el mundo, siempre estamos en "un lugar", tanto como siempre estamos en la cultura. Por esta razón, nuestras relaciones con el lugar y la cultura se convierten en elementos en la construcción de nuestras identidades, individuales y colectivas (Entrikin, 1991)

La geógrafa Doreen Massey relaciona estos dos conceptos al referirse a la identidad de un lugar sin estar arraigada simplemente dentro del lugar, sino que está compuesta también por relaciones externas (...) Expresa que:

"no hay lugares que existan con identidades predeterminadas que luego tienen interacciones, sino que los lugares adquieren sus identidades en muy buena parte en el proceso de las relaciones con otros. En definitiva, lo local y lo global se constituyen mutuamente". (Massey, D., 2004, pp.77-84)

Destacar al mismo tiempo la diferencia entre el lugar y el concepto de barrio. Dependiendo de la disciplina que lo estudie, geografía, arquitectura, sociología, antropología urbana, historia, entre otras su definición conlleva unos elementos u otros, pero todas parten y definen al barrio como subdivisión de una ciudad o pueblo, que suele tener identidad propia y cuyos habitantes cuentan con un sentido de pertenencia.

Tapia (2003) lo define "el barrio como la última trinchera de resistencia de las relaciones de proximidad, y los valores ligados al arraigo, la identidad, la memoria y la pertenencia".

En cuanto al concepto de barrio con identidad e historia propia, la definición de Park y Burgess (1984: 6, en Tapia 2013) : “(...) aquello que al principio era solo una expresión geográfica se transforma en un barrio, es decir, en una localidad con su propia sensibilidad, sus tradiciones y su historia particular". 
Massey (2004, p.77-84) propone una alternativa de barrio abierto y relacional indicando que el barrio, como lugar, se puede comprender como un punto de intersección de relaciones sociales en un momento dado, relaciones sociales que se extienden a una escala mayor que las que definen ese lugar en ese preciso momento. Esto implica "abrir" el barrio, tanto en el tiempo como en el espacio; es decir, el barrio se construye y se modifica en relación al presente, al pasado y también al futuro, pero también en cuanto a la proyección de esta intersección de factores a todas las escalas.

Otro de los elementos a analizar es el de prostituta, pieza clave cuando hacemos referencia a los conceptos de identidad y lugar. Del latín prostituta es la mujer que por su cuenta o por beneficio compartido por quien la explota, comercia con su cuerpo, permitiendo el acceso carnal por un precio con cualquiera que lo solicite.

Definiciones de prostituta como "la mujer que tiene relaciones sexuales con diferentes hombres a cambio de una remuneración económica" (Enciclopedia Internacional de las Ciencias Sociales, Vol. 8, 1979, p.476). Así como la reciente conceptualización que hace del término la Real Academia Española (2018) que la define como la "persona que mantiene relaciones sexuales a cambio de dinero", estableciendo una relación de género.

Por último dentro de las conceptualizaciones, y parte fundamental del proceso prostitucional e inherente a ello, es la violencia como parte integrante del mismo.

Violencia: multifacética, tras haber sido abordada por diferentes disciplinas y autores que la han leído de diferentes maneras y en distintas manifestaciones. Así podemos hablar entonces de violencia simbólica, estructural, cultural, directa o indirecta, visible, invisible, física, sexual, psicológica, económica, patrimonial, de género, pública, privada, etc.

Pero, independientemente de cual sea su valor, en todas se incluyen el poder y la dominación como partes integrantes de la misma. Max Weber (1996, p.43) los define:

Poder: significa la probabilidad de imponer la propia voluntad, dentro de una relación social, aun contra toda resistencia y cualquiera que sea el fundamento de esa probabilidad.

Dominación: debe entenderse la probabilidad de encontrar obediencia a un mandato de determinado contenido entre personas dadas.

La violencia ha sido definida por Concha-Eastman, 2002, p.44 :

"un acto intencional del poder y la fuerza con un fin predeterminado, por el cual una o más personas producen daños físicos, mentales o sexuales, los cuales lesionan la libertad de movimiento o causan la muerte de personas, a veces incluyéndose ellas mismas; estos actos violentos suceden en el hogar, en lo público o en el grupo"

Lagarde (1990, p.279) hace referencia a la violencia de la mujer expresando que "es de distinta índole y adquiere diferentes manifestaciones de acuerdo con quién la ejerce, contra qué, tipo de mujer, y la circunstancia en que ocurre", y concretiza respecto a la violencia erótica como "síntesis política de la opresión de las mujeres (...), que sintetiza en acto la cosificación de la mujer y la realización extrema de la condición masculina patriarcal". 
Importancia de la violencia como acto del desarrollo prostitucional, donde tanto el poder como la dominación están presentes durante todas las etapas del mismo. El primero se presenta de forma explícita en la violencia física; la segunda es constante bajo las formas de amenazas, promesas, engaños, miedo, etc. Con el poder se obliga, con la dominación se convence a la víctima, lo que es relevante esta distinción en el fenómeno estudiado porque puede dar origen a la discusión entre prostitución libre y forzada.

Como podemos ver, hay gran diversidad de posibilidades de conceptualizar estos elementos, pero hemos escogido los anteriores porque consideramos que tiene validez que va más allá del habla coloquial y permiten aplicarlos en estudios de carácter formal.

El fin de este marco conceptual es reflejar la base teórica del concepto de identidad de un lugar y así poder establecer los elementos que configuren la identidad del espacio de una mujer prostituta, para llegar a entender la búsqueda de la figura perdida en la infancia.

La prostitución como fenómeno y realidad social desde la antigüedad, ha estado marcado en la vida de cada una de las mujeres desde la infancia, por episodios temporales o continuos de violencia principalmente física, por parte del género masculino, a través de la figura del padre, cónyuge e incluso hijos, y el maltrato por parte del género femenino, desarrollado en muchos casos en base a una falta de afectividad familiar desde su nacimiento ,tanto por parte de sus madres, abuelas, hermanas y amigas. Este maltrato al que se ven sometidas, dejarán una huella de por vida en las mismas, e impregnarán falta de afecto y carencias propia en las mujeres prostitutas, que verán desarrollada a lo largo de su espacio y desarrollo vital, mostrando su grado de vulnerabilidad desde siempre, provocando al mismo tiempo una ruptura de identidad natural.

Establecer al mismo tiempo una diferenciación clara en el tipo de maltrato a la mujer antes de la prostitución, es poder entender el arrastre y vacío afectivo que van a tener a lo largo de la trayectoria vital de cada una, por ello, poder reflexionar sobre ello, nos ayudará a entender la causa de su entrada en el mundo de la prostitución, carente de todo afecto.

\section{APORTES PRÁCTICOS EN BASE A ENCUESTAS Y ENTREVISTAS PERSONALES A MUJERES PROSTITUTAS DE LA CIUDAD DE MÉXICO}

La metodología utilizada se centra en los datos obtenidos de 50 encuestas y 9 entrevistas personale realizadas a mujeres adultas que se prostituyen en dos zonas de la ciudad de México, pudiendo confirmar que antes de entrar en la prostitución la práctica totalidad de las entrevistadas han sufrido algún tipo de maltrato, sufriendo 8 agresión física, en concreto golpes, 16 violación, 5 de ellas acoso, y el 21 restante entrarian en la categoría de otros, donde estaría la agresión verbal principalmente ( encuestas: de elaboración propia en el Programa Universitario de Estudios de Género de la UNAM). 
Maltrato en sus diferentes aspectos que nos acercan a la problemática de la prostitución y a la repercusión que tiene en las mujeres que la ejercen, marcando su trayectoria de vida. Hacemos referencia con ello, al maltrato o violencia física que define Cervantes et al, 2004, p.243: "aquella que incluye acciones que por lo general se conforman en una escalada que puede comenzar por un pellizco y continuar con empujones, bofetadas, puñetazos, patadas y torceduras, pudiendo llegar hasta el homicidio".

Otro de los maltratos a los que se ven sometidas las mujeres prostitutas y que dejan huella en sus vidas, es el emocional o afectivo, donde el daño que produce y los medios que se utiliza, se encuentran en la esfera de lo emocional.

Varias son las manifestaciones del maltrato emocional destacando entre las mismas las devaluaciones verbales, a través de burlas, menosprecios, insultos; conductas amenazadoras a través de objetos como palos, cinturones, que muestran la forma de dañar profundamente a la mujer; intimidación, a través de expresiones verbales, gestos o conductas con el fin de provocar daño emocional o físico grave en la mujer (golpes, homicidio); hostilidad, provocando a través de gritos e insultos el miedo en la mujer y por último, expectativas abusivas, con el fin de prohibir y controlar a la mujer tanto en el ámbito público como privado.

Destacar las palabras de una sexoservidora en la entrevista personal realizada, cuando se hace referencia al maltrato por parte del cónyugue antes de entrar en la prostitución: "tuve cinco hijos, mi marido me pegaba y me amenazaba seguidamente...” (Julieta, 40 años).

Otra de las tipologías de maltrato es la violencia sexual, que se da cuando el hombre obliga a la mujer a tener relaciones sexuales sin su consentimiento, en contra de su voluntad, y que lleva intrínseca una violencia psicológica o emocional. Es una forma de violencia que consiste en "la imposición de relaciones sexuales por parte de la pareja masculina” (González, 2004, 170).

Mencionar a otra de las sexoservidoras cuando habla de su primer marido, y antes de entrar en la prostitución: "recuerdo a mi ex-marido, con el que tuve diez hijos, me maltrataba físicamente, mira las cicatrices. A los dos días de dar a luz me obligó a tener relaciones sexuales, tengo muy malos recuerdos de él..." (Carmen, 47 años).

Y, por último, cabe destacar otro tipo de maltrato, no menos importante y que entra en cohesión con los otros tipos de violencia, es el maltrato o violencia económica, que tiene como finalidad controlar por medio del ejercicio del poder que da la diferencia de género. El fin es "someter a otra persona mediante el control de determinados recursos materiales-dinero, bienes, valores- que pertenecen al agresor o a la víctima" (Torres, 2001, p146).

Esta violencia de partida en las mujeres prostitutas, tiene su origen en la mayor parte de los casos en la infancia al pertenecer a familias desestructuradas, con falta de afectividad y fuerte desarraigo familiar. La figura paterna ha estado marcada por su ausencia, debido a muerte, abandono de hogar o al no reconocimiento de su paternidad, pero en otros casos, la representan como idealizada y mítica en casi todos los relatos de las mujeres que ejercen la prostitución. Pero es indudable, que algunas mujeres se reflejan en el 
padre, que como ella, ha sido también, víctima de las circunstancias, y no lo juzgan, no lo cuestionan, no lo reprochan, recordándolo como algo preciado y valioso que alguna vez se tuvo. Estos casos solamente se presentan en una minoría de las mujeres, pero importante destacar para poder entender su condición y falta de afecto.

Esa infancia de padre ausente, idealizado y mitificado, es ocupada por el padrastro, que en ningún caso se torna en una figura masculina querida o amable. Normalmente, a partir de este sujeto, las mujeres crean una imagen negativa del mismo, motivada en su mayor parte por el maltrato que los mismos hacen de las niñas, mujeres de sus parejas. Figura temida y despreciada, amenazando la integridad física, emocional y sexual de las mismas, y que coerciona o ejerce violencia intrafamiliar continuamente.

Importancia de las palabras de una sexoservidora durante la entrevista personal con respecto a la agresión paternal sufrida y refiriéndose a su hija: "estoy pensando que mi hija está siendo violada (...), pienso que el que la puede estar violando es mi padrastro, lo mismo que me pasó a mi cuando tenía nueve años" (Edith, 25 años).

Destacan también las palabras de otra de las mujeres cuando hace referencia a antes de su entrada en la prostitución: "fui violada por mi padrastro, por eso protejo mucho a mis hijos para que mi compañero no intente hacer lo mismo, que ni los toque..." (Pati, 39 años).

Una característica a destacar en las mujeres que se prostituyen, al relatar episodios de su infancia, es la indiferencia e incredulidad de la madre ante el comportamiento abusivo de su pareja, jugando un papel de cómplice en el abuso de que son objeto sus hijas. El abuso sexual, e incluso, la violación hacia la hijastra, contaba con la complicidad de la misma.

Hablar de la figura paterna con estas mujeres, es reconocer el desapego afectivo con los hombres de su familia y, motivados por todos los episodios de violencia de los mismos, las referencias que hacen del padre son de tipo meramente descriptivas, con relación a sus actividades u ocupaciones, obviando detalles que solo relatarlos les causan dolor y sufrimientos con cada palabra.

Por lo tanto, entender la violencia hacia estas mujeres desde su raíz no es solamente tener presente al hombre, como actor principal de la misma, sino reflejar al mismo tiempo el maltrato femenino, de mujer a mujer, que se da desde la infancia en las mujeres que se prostituyen y que siguen arrastrando afectivamente en la actualidad.

Por consiguiente, es difícil poder llegar a entender la idealización social que atribuye a la mujer como valores positivos la bondad, la abnegación, la ternura...entre otras, al no permitir considerar el lado oscuro, pero que resulta significativamente destructora de subjetividades para varias generaciones de mujeres, marcadas por la violencia desmedida.

Violencia destructiva en estas mujeres y que tiene sus bases en un entorno familiar donde se experimentan privaciones emocionales profundas, y relaciones afectivas precarias con sus familias de origen.

Hablar de mujeres maltratadas, es entender cómo han crecido en un ambiente de violencia familiar extrema, ejercida en muchos casos, por la figura materna, debido a 
una ausencia sistemática por parte del hombre. La importancia de esta violencia radica en el sufrimiento y posterior desapego que han tenido estos sujetos, las madres, en sus trayectorias de vida, motivadas en cierta forma, por la también ausencia del varón, y desarrollando esa carencia en forma de maltrato hacia sus progenitores.

Las madres son mujeres que en su generalidad han sido abandonadas por el cónyuge y producto de estas relaciones frustradas, han quedado embarazadas o solas con hijos o hijas pequeños. De esta manera, la mujer que está ejerciendo, en su infancia se autopercibe como producto de un incidente y como símbolo de una pérdida y de una desgracia. Esta hija no deseada, ni querida, no solo representa el amargo recuerdo del pasado de la madre sino que se percibe como un impedimento, un estorbo para su futuro amoroso. Es a través de este sentimiento, cuando entra en juego la culpa de los males maternos y desarrolla en la misma un sentimiento de absoluta negatividad permanente, marcada por el dolor, la rabia y la tristeza.

Este comportamiento destructivo provoca en las mujeres un rechazo a la figura materna, aunque hay casos donde la idolatran y se reflejan en las mismas.

El rechazo afectivo que arrastran las mujeres que se prostituyen desde su infancia, es pieza clave para entender su entrada en el mundo del sexoservicio, mujeres que se sienten vacías afectivamente hablando, y que con por una necesidad de encontrarse con ellas mismas emocionalmente, así como por el apego al hombre, intentan sobrevivir en la prostitución, en muchos casos, por la búsqueda constante del sentimiento perdido después de tanta violencia.

Este proceso marca un antes y un después en la vida de las mujeres, anuladas sistemáticamente, violentadas, ultrajadas, con falta de afectividad y señaladas tanto en su vida privada como pública por el hecho de haber sido dominadas y marcadas por una opresión patriarcal. Diferentes autores hacen referencia a las causas de la entrada en la prostitución motivadas por una necesidad económica, problemas sociales, obviando las psicológicas, por ello la importancia de este artículo, en base a unas premisas generales de cómo estas últimas pueden ser motivo suficiente para el ejercicio de la misma. Ante la situación de violencia, las mismas mujeres se sientes rechazadas y sin opción de salida para poder subsistir y buscan en la prostitución su medio de vida.

Esta identidad propia que han construido en base a la violencia adquirida desde sus raíces, traerá consigo la ruptura de una identidad creada en base a mecanismos naturales, sociales, económicos, culturales y familiares lo que suele acontecer en todas las personas de manera general, identidad con la que se nace, y se va construyendo en función a lo vivido, provocando en estas mujeres prostitutas una falta de desequilibrio emocional que las hará buscar su punto central en el ejercicio de la misma. Importancia de la llegada a ella en base a una pérdida de la misma, sin personalidad, sumidas en una depresión, donde el miedo al sexo masculino en general, prima sobre todo lo demás.

Una vez dentro de este mundo, las ideas preconcebidas que podían tener sobre el mismo, basadas en los intentos de reconstrucción de su propia identidad, quedarán en un segundo plano y pasarán, en cierta forma, a seguir siendo víctimas de la violencia de 
género. Violencia en este caso marcada por sus parejas, en muchos casos sus proxenetas, así como por clientes. La presencia del género masculino y los miedos que llevan arrastrando, seguirán estando latente a lo largo de su trayectoria profesional. Este hecho, sin duda, no dejará impasible a las mujeres, que lucharán sin medida por no ser violentadas y estigmatizadas por parte de los mismos, así como de la sociedad en general.

Estos sujetos las maltratan, humillan, violan, las anulan y arrancan sus derechos como mujer, haciéndoles vacío permanente desde que nacen; pero no solo la figura del hombre provoca esto, también el género femenino, motivado en muchos de los casos, por el abandono de la madre, dejándolas carentes de afectividad provocando tristeza, angustia, depresión y omisión como mujer.

Prostitutas que buscarán en su radio de acción laboral su propia seña de identidad, a través de una reconstrucción de la misma o como le denominamos neoidentidad, intentando a través de lo que ellas designan "su punto" y con el que se reflejan diariamente, poder ser ellas sin filtros, sin doble personalidad, sin violencia, en base a una demanda constante no solo sexual sino también afectiva, y que lleva fracturada desde su infancia, perdurando en el tiempo.

Lucha diaria por ese "punto", como se refleja en las palabras de una sexoservidora: "estoy apoyando a Esther con lo del punto, y yo, Jasmine y Susana, las tres gays, la queremos y apoyamos" (Laura, 43 años).

Toda la violencia que se crea durante la infancia-adolescencia de las mujeres que se prostituyen, es lo que se pretende expresar en este artículo, provocando en las mujeres una pérdida de identidad que se creía propia, anulándolas de por vida y donde la reconstrucción de la misma será una lucha permanente. En la mayoría de los casos, la entrada en la prostitución se debe a este factor psicológico, la perdida de afecto y autoestima que en momento de depresión o fragilidad mental, acuden de manera directa o indirecta a ejercer la misma.

En este momento es donde se presenta los intentos de reconstrucción de esa identidad quebrada, a través del ejercicio de la prostitución, pero a partir de la misma entrarán en juego no solo factores afectivos, sino territoriales. Estas mujeres buscarán forjarse una identidad propia en base al dominio de territorialidad adquirida durante el ejercicio de su actividad.

Esa identidad de base, creada por medio de patrones educacionales, prácticamente en todos los casos, puede ser temporal o permanente y con el transcurrir del tiempo modificar o evolucionar, pero en determinados casos se puede fracturar motivados por fases de sufrimiento, dolor, miedo, impotencia, violación, humillación, entre otras causas, lo que puede provocar en esas personas un vacío como seres humanos, incapaces en muchos casos de controlar; a partir de esta situación es cuando la identidad que habían creado desaparece, sintiéndose anuladas y menospreciadas como personas, provocando una búsqueda sin igual por la reconstrucción de la misma, o de una nueva identidad.

Marcela Lagarde, 1990, p. 109 hace referencia a que: 
"cada mujer se constituye y tienen como contenido, como identidad, esa síntesis de hechos sociales y culturales que confluyen en ella y son únicos, excepcionales, pero, al mismo tiempo, por semejanza permiten identificarla con otras mujeres en situación similar"

Esta reflexión hace referencia a la experiencia particular de cada mujer, la cual está determinada por las condiciones de vida que incluyen, además, la perspectiva ideológica a partir de la cual cada una tienen conciencia de sí y del mundo, de los límites de su persona y de los límites de su conocimiento.

Esta teoría parte de la existencia de una identidad desde la infancia que se va creando en función de factores internos, desarrollados en la propia persona, como externos, a través de los diferentes agentes sociales con los que se relacionen.

Pero en el caso de las mujeres que se prostituyen, esta identidad creada desde la infancia se quebrará y desaparecerá, convirtiéndolas en objetos, cosificándolas y anuladas afectivamente hablando.

Estas reflexiones reales sobre las condiciones naturales de las mujeres se verán marcadas por una opresión patriarcal constante, generándoles conflictos y dificultades con su identidad femenina. Por lo tanto, hablar de la identidad de la mujeres es hablar de las prostitutas y como por el simple hecho de nacer mujer tienen forjada su propia identidad, en base a los factores sociales, psicológicos y familiares, formando una identidad propia y que las marcará de por vida.

Entra las causas más importantes que inducen a la prostitución están aquellas que arrastran una infancia robada afectivamente hablando, como destacamos en anteriores líneas, debido a las deficiencias en el ámbito familiar desde edad muy temprana, y que provocan motivaciones psicológicas, emocionales y morales que inducen a una persona a ejercer la prostitución.

La falta de respeto a las normas y valores sociales, así como la falta de confianza y afecto propio, las frustraciones emocionales, le hacen buscar el afecto del que carecieron. Esta falta de ambiente emocional deriva de una mala relación familiar marcada por un abandono de los padres, principalmente de la figura paterna, lo que puede inducir a la búsqueda de una ayuda emocional fuera del ámbito privado, y que cubra las necesidades que no tuvieron.

No solamente se debe al abandono intrafamiliar afectivamente hablando, la entrada de muchas de las mujeres en el mundo de la prostitución vienen marcada por una violencia sin igual, proveniente no solo del padre, a través de maltratos psicológicos, sino también físicos por parte de hermanos, parejas e incluso del sexo femenino, como hemos podido comprobar a lo largo de las diferentes investigaciones realizadas.

Estos signos de violencia marcarán la vida de las mujeres y a posteriori, arrastrarán durante toda su vida. La fragilidad no solo emocional sino también física en la que quedan sumidas desde la infancia, dejarán huella de por vida, intentando luchar contra el sexo opuesto en la mayor parte de los casos, no solo por su condición de mujer, luchando du- 
rante toda su vida por una igualdad sin límites, sino por su entrada y ejercicio de la prostitución, la cual las estigmatizará, infravalorará, violará sus derechos como ser humano, y determinará su condición femenina durante su trayectoria vital.

Está falta afectiva en la mujer prostituta mantendrá una búsqueda constante de estabilidad emocional, aunque su propia actitud se lo impida, marcada en parte, por un sufrimiento constante en sus años de desarrollo no solo mental sino personal, una perdida de libertad que las ha llevado a una lucha diaria con el miedo, a un rechazo al sexo opuesto por toda la violencia ejercida sobre ellas, y por consiguiente a un rechazo social.

Mujeres que han quedado marcadas y con una gran falta autoestima, que las hace vulnerables y frágiles y sienten como la sociedad las rechaza por el hecho de haber sido maltratadas y ultrajadas durante toda su vida, y más aún desde que se dedican a la prostitución, actividad que tras años de lucha por ser reconocida como una actividad más, las prostitutas siguen siendo en muchas sociedades, parte no necesaria de una sociedad limpia. Es por ello, que se colocan al margen de esa sociedad que las critica, las manipula, las olvida, sintiéndose totalmente rechazadas.

Por ello, unos de los factores fundamentales que predisponen la adopción de la prostitución como forma de vida es hecho de que durante la infancia, estas mujeres han tenido un fuerte y marcado rechazo por parte de la figura paterna, o bien, la falta de una figura materna de identificación más o menos positiva, lo que les impide la internacionalización de un rol femenino claro y definido que a su vez les permitiera relacionarse con el hombre de manera adecuada.

Paralelamente a la ausencia de marcos de referencia en relación a los papeles designados al hombre y a la mujer, se encuentra un deseo inconsciente de agresión y venganza hacia el padre que la privó de su amor, y que proyecta a la gran mayoría de los hombres que conoce y trata.

Por todo ello, en las mujeres prostitutas se observan también intensos sentimientos de devaluación, menosprecio y violencia, cuyo origen generalmente se encuentra en el rechazo tan marcado por parte de los padres. Esto puede verse en la relación que la prostituta establece con el cliente, en la que aquella se le suele tratar como mercancía desde el momento en que, a cambio de determinada suma de dinero, el hombre puede utilizar el cuerpo de la misma para su satisfacción personal.

Así lo reflejan las palabras de una de las mujeres cuando hace referencia a uno de sus clientes: "un día uno de mis clientes me sacó una pistola..." (Esther, 27 años).

Otra experiencia de una sexoservidora:

“me llevó a un sitio desconocido donde nadie nos podía ver, allí me empezó a golpear, primero con la mano, y seguido con un bate de beisbol que tenía guardado, primero me dio en la cabeza y luego en las costillas" (Jessica, 30 años)

Mujeres que han desarrollado su vida en una atmósfera pervertida en las que se han sentido víctimas de la superioridad de un hombre, sea por seducción, ataque sexual o violencia, ocasiona que ya desde la infancia empiecen a revelarse contra su papel femenino. 
Todas estas carencias en el plano de la afectividad que las llevan a ejercer en cierta forma la prostitución y sentirse violentadas, humilladas desde su infancia y durante el ejercicio de la prostitución, unidas a la necesidad económica, dan como resultado la integración de una personalidad conflictiva, y se manifestará a través de una serie de características psicológicas como una falta de afecto, que las lleva a la necesidad de sentirse queridas al haber sido anuladas desde su infancia; pero aun así, privadas por este fracaso emocional, se sienten en la mayoría de los casos incapaces tanto de dar como de recibir afecto de otras personas, y con malestar en sus relaciones.

Otra de las características psicológicas por las que pasan es por la ansiedad, atribuida a la inestabilidad de la situación en la que se encuentran, y motivada en cierta forma por las agresiones verbales y físicas a las que se han visto sometidas, al mismo tiempo que tienen episodios constantes de depresión, surgidos tras esa falta de afectividad familiar y con brotes de soledad tristeza. Estás características son claves en las mujeres que sufren cualquier episodio de violencia, y tras sentirse humilladas y ultrajadas por los diferentes actores sociales, en concreto por los hombres de su círculo de acción, pasan por una fase de depresión donde pasan a formar parte del papel de víctimas, sentirse despreciadas por su familia, y por la sociedad en general, perdiendo su propia identidad, aquella que construyen cuando se nace y que fracturan en base a la violencia adquirida desde su infancia.

Esta violencia genera situaciones de frustración y fracaso en las prostitutas, motivadas por episodios de insatisfacción con lo que han logrado en su vida, considerando que han fracasado como madres, como mujeres, lo que provoca en las mismas un sentimiento de rechazo, agresión y animadversión ante cualquier estímulo.

La existencia, como otra de las características, del sentimiento de culpa que arrastran. Son mujeres que promovidas por una falta de afectividad a la par que económica, comienzan a ejercer la prostitución y sienten que por ello han fallado o traicionado a sus familias, principalmente a sus hijos.

Mujeres que han estado y están marcadas por fases violentas, y sin opciones de futuro, con falta de ayuda parental para desarrollarse en la vida y sin ningún tipo de ayuda económica, tan acuciante que arrastran y que las sumerja de la situación en la que viven, unido a la falta de afectividad y cariño por parte de los suyos y sumado a la violencia que sufren por el hecho de sentirse menospreciadas por una sociedad machista que las manipula, viola, y extorsiona, ven en la prostitución la única salida a su tan precaria vida, y es ahí cuando su sentimiento de culpa se hace todavía más latente, sintiéndose culpables de la situación en la que viven.

Como se puede apreciar, todas estas características que arrastran las mujeres que se dedican a la prostitución, tienen su origen en la falta de afecto por parte de sus familias que las hacen sentirse vulnerables ante cualquier situación y más aún, durante el contacto con el sexo masculino.

Este tipo de desprecio y animadversión de los hombres hacia las prostitutas las hacen sentirse rechazadas y responder al mismo tiempo, en base a agresiones también. 
Existe en algún caso reciprocidad en los hechos, motivadas en cierta forma por la lucha de esa identidad que están perdiendo.

Estos signos de violencia y por consiguiente el ejercer la prostitución expresa una innegable actitud de autodestrucción, indicando un desequilibrio en la persona debido a severos conflictos internos no resueltos por las propias mujeres y que en general, se suscitaron desde la infancia e impidieron a la persona evolucionar normalmente, es decir, tener una conducta adaptativa consigo misma y con el mundo externo.

Por todo ello, en base al marco teórico expresado en las líneas anteriores, podemos entender cómo la mujer prostituta, independientemente de la edad que tenga, y a través de su lucha diaria por sobrevivir, se forja un espacio en el cual desarrolla su actividad convirtiéndolo en centro de su vida. A través del mismo, la mujer prostituta, y debido a un sentimiento al lugar, se va apegando al mismo formando una identidad propia, no sólo individual, por su relación privada con el espacio, sino colectiva, por los relaciones externas que se dan en el mismo, y que le dan una seguridad y una pertenencia imaginaria del espacio.

Esta lucha por la identidad de un lugar de la sexoservidora tiene su base, prácticamente todos los casos, en los primeros años de su vida, donde poco a poco va creciendo un sentimiento de falta de identidad, de espacio para realizarse, junto con una pérdida de la autoestima. La ausencia del padre, los abusos sexuales que padecen, la violencia familiar, las sucesivas rupturas afectivas, acaban por reforzar una profunda sensación de abandono. Marginación marcada por sus continuas idas y venidas, así como vagabundeo, padeciendo un sufrimiento de origen social y afectivo.

En ellas destaca un alto nivel de vulnerabilidad que les impide integrarse en la sociedad, convirtiéndolas en presa fácil para el sistema de la prostitución, que se presenta como una solución de supervivencia, pero que en realidad, solo conduce a la marginación y a la exclusión.

Esta pérdida de identidad en sus primeros años de vida, les llevará, una vez entradas en el mundo de la prostitución, en la lucha continua por una identidad perdida, en base al espacio de trabajo, al lugar donde desarrolla su actividad, a su punto de encuentro, y al "punto" de dominio.

Arturo-Zarama y Cante-Maldonado, 2017, p. 73 hacen referencia a diferentes movimientos a favor o en contra de la existencia de la prostitución, y la construcción de identidad por parte de las prostitutas, los cuales datan de los años 80 del siglo XX.

El International Committee for Prostitute's Rights creado en 1985 por prostitutas de todo el mundo. Este movimiento se apropió del término prostituta para darle un significado positivo, contrapuesto a la definición y concepto que había hasta el momento, y disociado de la definición de enfermo y contaminante que cargó durante el siglo XIX.

El International Committee for Prostitute's Rights definió el sexo como un regalo sagrado y como una parte esencial que nutre la vida, por lo tanto, el sexo comercial es un beneficio para la humanidad, y empodera a los trabajadores sexuales definiéndolos como "educadores de sexo seguro". Adicional a lo anterior, el International Committee 
for Prostitute's Rights demanda para las prostitutas los mismos derechos civiles que posee cualquier otro trabajador, además de la descriminalización, dado que el movimiento considera la prostitución una elección voluntaria en la medida en que otras son libres en el sistema racista, patriarcal y capitalista de hoy en día.

Como oposición a la anterior visión de la prostitución, el movimiento WHISPERS (Women Hurt in Systems of Prostitution) formado en 1995 en Estados Unidos, definió a la prostituta como una víctima, pues para este movimiento no existe una diferencia entre prostitución voluntaria y forzada, ya que las mujeres dedicadas a esta ocupación están sujetas a actos sexuales que en otros contextos serían percibidos como coercitivos. Adicionalmente, y en contraste al International Committee for Prostitute's Rights, WHISPERS rechaza la palabra prostituta para darle identidad a quienes cambian servicios sexuales por dinero, puesto que para el movimiento esta palabra representa más bien la ausencia de identidad, porque estas mujeres suelen cambiar sus nombres, y apariencias, crean un pasado ficticio, y así facilitan que los hombres proyecten sobre ellas su dominio sexual (Bell, 1994).

Desde ésta óptica le damos valor a las palabras de Doreen Massey, 2004, p. 79 en cuanto a identidad se refiere, identidad creada en base a una relaciones que se establecen entre el individuo y el espacio, espacio donde se insertan unas relaciones externas que lo hacen tener vida, creación de espacio único y diferente a los que lo rodean, pero no necesariamente individual, pues parte de lo global y de la relación con el individuo. Explica que la identidad de lugar:

"no está arraiga simplemente dentro del lugar sino que está compuesta también por relaciones externas (...), no hay lugares que existan con identidades predeterminadas que luego tienen interacciones, sino que los lugares adquieren sus identidades en muy buena parte en el proceso de las relaciones con otro"

Para Massey (Vidal, D.A.,2015, p.171), a través del concepto de "geometrías de poder":

"es necesario comprender y vivir el espacio como una necesidad ontológica, vital y con capacidad de mutabilidad para la diversidad de actores y trayectorias espaciotemporales, y que se presentan como oportunidades de resistencia, lucha y solidaridad, que lleva a repensar las dinámicas locales como resultado de relaciones globales interconectadas y atravesadas por relaciones de poder"

A través de estas palabras, la teoría de Massey se puede reflejar en el sector investigado, donde cada mujer prostituta se forja una identidad, en un espacio llamado lugar, a través de las diferentes relaciones tanto locales como globales, mediante un escenario donde los diferentes actores y subjetividades interactúan, donde estas mujeres viven su espacialidad, y manifiestan en ella sus percepciones, sentimientos, afinidades con los demás actores y el entorno en que se mueven, manifestando así su lugar como familiar, próximo y local. 


\section{DOMINIO DE TERRITORIALIDAD Y RECONSTRUCCIÓN DE IDENTIDADES EN LA PROSTITUCIÓN DE CALLE}

Esta búsqueda por parte de estas mujeres, nos lleva a explicar el dominio de territorialidad por parte de las mismas y que representa una identidad propia, de manera individual, en su zona de trabajo, como lugar de resistencia y de lucha, donde reflejan los sentimientos, encuentros y desencuentros, al mismo tiempo que colectiva, en el grupo al que pertenecen, forjando un espacio exclusivo donde poder desarrollar su actividad en función a como han sido concebidos y vividos por las mujeres.

Esto explica la búsqueda de un espacio definido y de identidad con el mismo, ya sea como víctimas del mismo o como centro de lucha personal, a través de las interrelaciones existentes en el espacio con los diferentes actores que lo conforman.

Por todo ello, nos referimos a la prostitución, aquella que ocupa espacios específicos dentro de un territorio, generando conflictos en las zonas donde se ubican, aunque en la mayor parte de los casos se llega a coexistir con el resto de actividades del barrio. Es la ocupación de la misma en un espacio denominado lugar donde las mujeres forjan su identidad, marcada por un sentimiento de pertenencia al mismo.

Esta actividad se desarrolla en una calles determinadas, y una clara delimitación geográfica que aun siendo imaginaria, la hacen como propia. A partir de esta connotación es importante destacar la relación existente que se aprecia entre la prostitución y el espacio, entre la prostitución y el área donde ejercen la actividad, punto neurálgico del ejercicio de la misma, y que la hacen "imaginariamente" como propia.

Las mujeres prostitutas conforman la existencia del apego al lugar y por consiguiente, la identidad de lugar a través de procesos que dan cuenta de la interrelación de ellas con el entorno, haciéndolos propios. Importancia de los vínculos entre las personas y los espacios, entendidos como construcción social de lugares, de donde se destacan el espacio simbólico, la identidad y el apego al lugar como principales conceptos.

Importancia de una investigación donde se relacionen las experiencias cotidianas y las nociones de lugar que construyen las personas, enfatizándose las nociones que se desarrollan del espacio, así como las emociones, pautas y sentimientos que en él se dan. Cabe destacar las líneas de investigación al respecto de Pol (1996), Valera(1993), Vidal (2002) .

A través de estos teóricos podemos reflejar ese sentimiento de propiedad que generan estas mujeres que se prostituyen, haciendo ese espacio geográfico propio, espacio imaginario donde desarrollan su vida, días y noches donde reflejan los sentimientos tanto públicos como privados, donde se sienten seguras de poder ser ellas, en un espacio creado para tal fin. Necesidad de las mujeres de desarrollar su labor, así como su vida en general, en un espacio creado por las mismas que denote su presencia, su imagen real e imaginaria que la sociedad haga de ellas, así como su personalidad.

Estas mujeres buscan y conforman su propia identidad bajo diferentes relaciones sociales, y siempre en función del entorno y los factores que le rodeen. Importancia del 
espacio no como algo estático, sino como parte de un conjunto, dependiente en la mayor parte de lo que les rodea.

Lo físico, lo material, los sentimientos, las percepciones, los miedos, las inseguridades, el poder, la familia, el trabajo y las relaciones con los demás, entre otros. Esto hará que se creen en ellas un sentimiento de propiedad nunca antes percibido, pero que gracias a él provoquen una autodefensa y lucha por su espacio, creado año tras año, y que sin ser legal les da identidad propia.

A este espacio es al que las propias mujeres designan como "punto", zona de trabajo donde desarrollar su faceta como prostitutas, donde poder mostrarle a la sociedad que son las dueñas del mismo, y donde crear su realidad e incluso su imaginación, pero siempre bajo el dominio de poder.

Destacar al grupo de teóricos que defienden la transformación del espacio a través de la acción sobre el entorno, las personas, los grupos y los colectivos, dejando en el su huella, con marcas y señales simbólicas. Pol (2002, pp. 123-132) defiende que las acciones dotan al espacio de significado individual y social, a través de los procesos de interacción, y Valera (1997) defiende que las personas y los grupos se autoatribuyen las cualidades del entorno como definitorias de su identidad.

Estos autores, al mismo tiempo, hacen referencia a los procesos de apropiación del espacio y apego del lugar como procesos dinámicos de interacción conductual y simbólica de las personas con su medio físico, por lo que un espacio llega a ser un lugar, cargándose de significado y percibido como propio por la persona o el grupo, integrándose como elemento representativo de identidad.

Siendo a través de esta identificación donde entra en juego el papel de la prostitución, y en concreto de la mujer prostituta, concibiendo el lugar de trabajo, donde ejerce y desarrolla su actividad, como parte integrante de su vida, y aunque refleja lo imaginario, destaca por su valor de identidad, de poder, de único donde forjar su espacio permanente vital.

Para ello se interrelaciona los aspecto sociales que hacen que el lugar destaque por su poder de control e identidad, de desarrollo de sentimientos, apegaos, afines que se hacen en el mismo como consecuencias de las experiencias diarias de estas mujeres.

La prostituta y el espacio donde ejerce, adquiere en los hombres un aura mágica en donde la mujer tiene que ser incontrolable, insaciable y es en este espacio, donde la mujer tiene un particular lenguaje, posturas, comportamientos, actitudes. Así lo refleja Marcela Lagarde y de los Ríos, 2011, p.603 al referirse a la de construcción de identidad por parte de las prostitutas:

\footnotetext{
"La subjetividad de las prostitutas concreta el proceso de construcción de una identidad que expresa la prostitución como el núcleo definitorio de todos los hechos de su vida. Como algo más que un oficio, una habilidad, un trabajo, una ocupación, o actividades..."
} 
A modo de conclusión, podemos confirmar la búsqueda incansable de estas mujeres por la reconstrucción de una identidad marcada en sus inicios por episodios de falta de afectividad y violencia, reflejo de las 50 encuestas realizadas a mujeres que se prostituyen de la Ciudad de México, así como a las 9 entrevistas personales que completan la información y concluyen expresando las agresiones sufridas antes de su entrada en este mundo, y las consecuencias que arrastrarán de por vida con intentos de reconstrucción constantes y necesidad de un espacio donde desarrollarse física y psicológicamente.

Al mismo tiempo, en base a los datos analizados y a las experiencias de vida de las mujeres prostitutas, las mujeres prostitutas se reflejan como poseedoras del control espacial en el cual ejercen su actividad, proclamándose dueñas del mismo, y aunque muchas veces invadido por agentes externos, luchan para seguir con el dominio de "su territorio". Por momentos son cercadas o perseguidas perdiendo su espacio, la policía, los clientes, los proxenetas, incluso la población en general y sus compañeras, en muchos casos hacen que ese dominio y poder que tiene de la propiedad desaparezca, y por consiguiente pierdan su identidad.

La defensa que hacen del espacio de trabajo, así como del desarrollo de su actividad y por defecto, su creciente imagen e identidad, hace que por momentos se debilite debido a estos agentes, y ese sentimiento que generan en las mujeres, de pérdida de la identidad espacial, genera un discurso de defensa y delimitación de un territorio propio, donde ejercer la prostitución sin la intervención de agentes externos perturbadores.

Muchas mujeres se proponen redefinir de manera individual en casi todos los casos, pero igual colectivamente, con el fin de cambiar la imagen del marco espacial y conquistar una sensación de tranquilidad y seguridad que parece perdida a día de hoy, debido a los niveles de delincuencia, inseguridad y desconfianza que se da en él.

Aunque la lucha por la identidad del lugar de estas mujeres es cada vez más fuerte y el apoyo global que están teniendo en los últimos años va en aumento, estas perturbaciones hacen que el equilibrio que se estaba manteniendo hasta ahora se rompa, y se hable de la necesidad de una nueva definición espacial y mayor movilización.

A partir de esta reflexión, la importancia del llamado "punto" por estas mujeres tiene su raíz en esta búsqueda de la territorialidad. Mujeres que han sufrido durante toda su vida, desde una doble vertiente, por un lado por ser mujeres mostrándose durante años impasibles, por miedo, vergüenza, abusos, violaciones, desarraigos, maltratos, entre otros y por otro lado y, más aún, desde que ejercen la actividad, motivadas por una fuerte estigmatización, han decidido sacar la fuerza y el valor para luchar por su dignidad, a través de lo que consideran su dominio en base a la neoidentidad. 


\section{BIBLIOGRAFÍA}

Arturo, D. y Cante, F.E. Prostitución y desigualdad socioeconómica. Revista Eleuthera, 16,año 2017, pp. 69-84.

Bákula, C. Reflexiones en torno al patrimonio cultural. Revista Turismo y patrimonio, número 1, año 2000, pp.164-167.

Bell, S. Reading, Writing, and Rewritting the Prostitute Body. Indiana, EU: Indiana University Press, 1994.

Cervantes Muñoz, Consuelo, Luciana Ramos Lira y María Teresa Saltijeral, "Frecuencia y cronicidad de las modalidades de violencia emocional ejercidas por el compañero en el último año", Marta Torres Falcón, (compiladora) Violencia contra las mujeres en contextos urbanos y rurales, El Colegio de México-PIEM, México, 2004, pp. 239-270.

Concha-Eastman, Alberto, "Urban Violence in Latin America and the Caribbean: Dimensions, Explanations, Actions", Susana Rotker (editora) Citizens of Fear, Urban Violence in LatinAmerica, Rutgers University Press, New Jersey, 2002.

Enciclopedia Internacional de las Ciencias Sociales, Vol. 8, 1979, p .476.

Entrikin, N. The Betweenness of place. The Johns Hopkins University Press, Baltimore, 1991.

González Montes, Soledad, "La violencia conyugal y la salud de las mujeres desde la perspectiva de la medicina tradicional en una zona indígena”, Marta Torres Falcón (compiladora) Violencia contra las mujeres en contextos urbanos y rurales, El Colegio de México-PIEM, México, 2004, pp. 153-194. https://doi.org/10.2307/j. ctv513792.9

Horton, J and Kraftl, P. Cultural Geographies: An Introduction. Capítulo 8, Identities. By Routledge, London 2013, pp. 344.

Kravzov Apple, E. Globalización e identidad cultural. Revista mexicana de Ciencias Políticas y Sociales, Vol. 46, No 187, año 2003. https://doi.org/10.22201/ fcpys.2448492xe.2003.187.42407

Lagarde, M. Identidad femenina, 1990 en Texto difundido por CIDHAL (Comunicación, Intercambio y Desarrollo Humano en América Latina, A. C. - México). http://www. laneta.apc.org/cidhal/lectura/identidad/texto3.htm

Lagarde, M y de los Ríos. Los cautiverios de las mujeres. Madresposas, monjas, putas, presas y locas. Madrid: Editorial San Cristobal, año 2001.

Larrain, J. El Concepto de Identidad. Revista FAMECOS. Comunicación y cultura, número 21, Porto Alegre, Alberto Hurtado, Chile, 2003. https://doi.org/10.15448/19803729.2003.21.3211

Massey, D. Lugar, identidad y geografías de la responsabilidad en un mundo en proceso de globalización. Treballs de la Societat Catalana de Geografía, 57, 2004 , pp.77-84.

Molano, L.O. Identidad cultural un concepto que evoluciona. Revista Ópera, No 7. Universidad Externado de Colombia, Bogotá, Colombia, 2007, pp. 69-84. 
Pol, E. La apropiación del espacio. En L. Iñiguez y E.Pol (Eds). Cognición, representación y apropiación del espacio. Col.lecció Monografies Psico-Socio-Ambientals (vol.9, pp.45-62). Barcelona: Publicacions de la Universitat de Barcelona.(Original, 1994, en Familia y Sociedad, 12,233-249), 1996.

Pol, E. El modelo dual de la apropiación del espacio. En R. García Mira, J.M, Sabucedo y J. Romay (Eds), Psicología y Medio Ambiente. Aspectos psicosociales, educativos y metodológicos (pp.123-132). A Coruña: Asociación galega de estudios e investigación psicosocial, 2002 .

Tapia V. El concepto de barrio y el problema de su delimitación/aportes de una aproximación cualitativa y etnográfica. Revista Bifurcaciones Vol.12, 2013.

Torres Falcón, Marta, La violencia en casa, Paidós Croma, México, 2001.

Valera, S. El simbolisme en la ciutat. Funcions de l'espai simbòlic urbá. Tesis Doctoral. Universitat de Barcelona, 1993.

Valera, S. Análisis de los aspectos simbólicos del espacio urbano. Perspectivas de la psicología ambiental. Revista de Psicología. Universitas Tarraconensis, 18, año 1996, pp. 63-84.

Valera, S. Estudio de la relación entre el espacio simbólico urbano y los procesos de identidad social. Revista de psicología Social, 12, año 1997, pp. 17-30 . https://doi. org/10.1174/021347497320892009

Vidal, T. El procés dápropiació de l'entorn. Una porposta explicativa i la seva contrastació. Universitat de Barcelona, 2002. Tesis doctoral publicada en línea, disponible en http://www.tdx.cesca.es

Weber, M. Economía y Sociedad. FCE. México, 1996. 